\title{
Problemas de linguagem em inglês aeronáutico: uma análise de comunicação técnica sob diferentes ramos linguísticos
}

\section{Language problems in aeronautical English: a technical communication analysis under different linguistic areas}

\author{
Gabriel Masid Gonçalves' ${ }^{1}$, Aline Pacheco² \\ Pontifícia Universidade Católica do Rio Grande do Sul (PUCRS). Porto Alegre, RS, Brasil. <gabriel.masid@hotmail.com> \\ 2 PUCRS. Porto Alegre, RS, Brasil. < aline.pacheco@pucrs.br>.
}

\begin{abstract}
RESUMO
Desde os engenheiros que constroem as aeronaves até os pilotos que as operam, a segurança vem, ou pelo menos deveria vir, em primeiro lugar, sendo de inegável importância para a aviação. Contudo, acidentes continuam acontecendo. Assumindo a premissa de diversas causas, e nunca causas isoladas, uma delas pode ser o erro de comunicações. $O$ tema a ser abordado tem como base os problemas de linguagem em inglês aeronáutico, caracterizando uma análise de comunicação técnica sob diferentes ramos linguísticos e possíveis acidentes decorrentes destes problemas. Os resultados foram obtidos por meio da organização sistêmica dos dados coletados, os quais foram alcançados através de pesquisas bibliográficas. Os acidentes, ou exemplos de possíveis miscommunications, foram categorizados de maneira a identificar a área da linguística envolvida neste processo. Em caráter geral, o objetivo proposto é analisar os problemas de linguagem em comunicação técnica aeronáutica em inglês, sob diferentes ramos linguísticos.
\end{abstract}

PAlavras-CHAVE: Ramos linguísticos; Análise; Organização; Acidentes; Miscommunication.

\begin{abstract}
From the engineers who build up the aircraft, to the pilots who make them fly, safety needs to be the first gold rule, or at least, it had to be so, once it's strictly important for the aviation industry. Nevertheless, accidents still occur. Believing there are always several causes for any accident, it is quite reasonable to think communication errors could be involved in this. The theme of this monography is entirely sustained on language problems in technical aeronautical English, which may unroll into an accident, and how to analyze this under linguistics optical methodology, given by different linguistic levels. The results have been gained by organizing specific bibliographic data, which encompasses examples of possible miscommunication and accidents. These accidents and examples had been linked with the different linguistic levels. Generally, the main goal is to analyze and organize the potential problems that may occur on technical aeronautical communication in English.
\end{abstract}

KeYwords: Linguistic levels; Analysis; Organizational; Accidents; Miscommunication.

Pontifical Catholic University of Rio Grande do Sul Porto Alegre, RS, Brazil

Editor

Thaís Russomano

Microgravity Centre PUCRS, Brazil

Executive Editor

Rafael Reimann Baptista

Faculdade de Educação Física e Ciências do Desporto, PUCRS, Brazil

e-ISSN: 2179-703X

\section{Corresponding Author: \\ Aline Pacheco \\ <aline.pacheco@pucrs.br> \\ Received:May 04, 2017 \\ Accepted: May 25, 2017 \\ (c) 2017 EDIPUCRS}

This work is licensed under a

Creative Commons-Attribution 4.0 International. http://creativecommons.org/licenses/by/4.0/ 


\section{Introdução}

O movimento frenético e dinâmico de pessoas, carga e informação é uma das maiores evidências da atual fase globalizada que vivemos.

No último meio século, segundo Griffin (2002), podemos analisar 25 milhões de viagens internacionais em 1950, contra 667 milhões de pessoas em viagem internacional em 1999. Ainda mais, é previsto que mais de 1 bilhão de pessoas cruzem fronteiras internacionais em 2020 a bordo de aviões. Números significativos para a economia global, movimentando bilhões de dólares todos os anos, sendo o transporte de pessoas e cargas um ramo de atividade que depende de um verdadeiro exército de funcionários. Pessoas aplicadas a um único propósito: realizar o transporte de maneira eficaz e, principalmente, segura. Desde os engenheiros que constroem as aeronaves até os pilotos que as operam, a segurança vem, ou pelo menos deveria vir, em primeiro lugar, sendo de inegável importância para a aviação.

Contudo, acidentes continuam acontecendo. Tendo diversas causas, e nunca causas isoladas, uma delas pode ser o erro de comunicações. Estas, especialmente entre pilotos e controladores de tráfego aéreo, segundo Kanki e Palmer (1993). Aeronaves modernas não podem ser operadas apenas pelos pilotos, estando estes sujeitos a informações, autorizações e instruções, advindas do controle do espaço aéreo. De maneira clara, seria ao menos plausível analisar os erros de comunicação que poderiam acontecer, colocando em pauta a margem de segurança que fora infringida. Por isso, o trabalho que aqui propomos visa a ligar problemas linguísticos a um possível acidente aeronáutico.

O tema a ser abordado tem como base os problemas de linguagem em inglês, caracterizando uma avaliação da comunicação técnica sob diferentes ramos de análise linguística e possíveis acidentes decorrentes destes problemas. Entenderemos por ramos linguísticos as diferentes perspectivas de análise da linguagem, ou seja, podemos analisar um determinado aspecto linguístico sob as perspectivas da sintaxe (foca a estrutura), semântica (foca o significado), fonética/fonologia (foca a pronúncia), e pragmática (foca o significado a partir de um contexto extralinguístico).

Podemos começar o debate do problema que este trabalho se propõe a discutir a partir da seguinte questão: quantos pilotos voando ao redor do mundo têm o inglês como L2 ${ }^{1}$ ? A Figura 1 mostra, em por-

\footnotetext{
${ }^{1}$ Para os fins deste trabalho, utilizaremos o termo L2 para referirmos à segunda língua adquirida por um determinado falante. Entenderemos L2 como sinônimo de língua estrangeira, conforme Ellis (1994).
}

centagem, o tamanho da população falante de cada língua. Vemos que, proporcionalmente, há mais pessoas cujo inglês pode ser apenas a L2 do que pessoas de inglês nativo. Deste modo, há a possibilidade de erros nas comunicações entre pilotos, ou entre pilotos e os órgãos de controle, abrindo uma brecha para que um acidente aconteça.

O problema que se apresenta é o uso do inglês em comunicação aeronáutica. Para esse fim, analisaremos o inglês aplicado tanto na condição de L2, como na condição de $\mathrm{L1}^{2}$, incluindo, por conseguinte, falantes nativos de inglês de diversas origens.

Figura 1. Análise das línguas e o número respectivo de falantes nativos

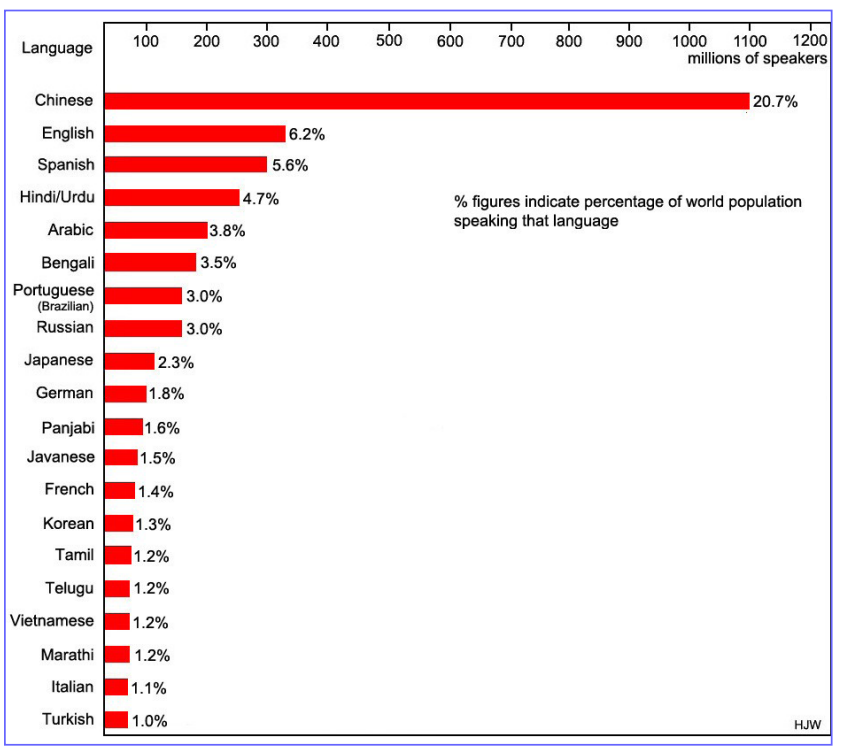

Fonte: Gunnemark (1991).

A partir do que acabamos de propor, a hipótese do trabalho é a de que relevantes problemas de comunicação, decorrentes do equivocado uso do inglês, seja como L1 ou L2, podem resultar em acidentes aéreos.

Em caráter geral, o objetivo proposto é analisar os problemas de linguagem em comunicação técnica aeronáutica em inglês como L1 e L2, sob diferentes ramos linguísticos.

\section{Pressupostos teóricos}

\subsection{Linguagem e linguística}

Como nosso início, temos a linguística, e serão pontuadas questões inerentes ao desenvolvimento

\footnotetext{
${ }^{2}$ Conforme UNESCO 2003, entenderemos o termo L1 como a primeira língua aprendida, por um determinado indivíduo, na infância. Ainda, L1 será aplicado neste trabalho como sinônimo de língua materna, de acordo com Spinassé (2006).
} 
coeso da pesquisa a ser realizada. Veremos características importantes, como as definições dos diferentes campos abordados pela linguística, a fonética, fonologia, semântica, pragmática e sintaxe. Utilizaremos, para os fins deste trabalho, os estudos da fonética e da fonologia complementares entre si, categorizando um único campo de análise, posteriormente, à pontuação dos acidentes. Ainda, conceitos como linguística por si própria, língua e linguagem devem ser pontos fundamentais de estudo.

Conforme Fiorin (2008), a linguagem sempre exerceu fascínio sobre o homem no sentido de ter a capacidade de não só nomear/criar/transformar o universo real, mas também trocar experiências, falar sobre o que existiu, poderá vir existir, e até mesmo imaginar o que não precisa nem pode existir. A linguagem verbal é, então, a matéria do pensamento e o veículo da comunicação social. Assim como não há sociedade sem linguagem, não há sociedade sem comunicação. Tudo o que se produz como linguagem ocorre em sociedade, para ser comunicação, e, como tal, constitui uma realidade material que se relaciona com o que lhe é exterior, com o que existe independentemente da linguagem. Como realidade material - organização de sons, palavras e frases - a linguagem é relativamente autônoma; como expressão de emoções, ideias, propósitos, no entanto, ela é orientada pela visão do mundo, pelas injunções da realidade social, histórica e cultural de seu falante.

O conceito de ambiguidade deve também ser analisado, dada sua íntima relação ao miscommunication. Conforme Cushing (1997), uma estrutura ambígua resultará de diferentes estruturas, as quais são possíveis diferentes interpretações decorrentes de uma estrutura principal. Tais estruturas se diferenciarão especificamente quanto suas análises sintáticas. No exemplo a seguir, retirado do livro Fatal Words, de Cushing (1997), podemos analisar a mesma frase sob duas estruturas distintas:

\section{Ex.: "Flying planes can be dangerous." (p. 7)}

Na primeira, temos "Flying" com classe gramatical de adjetivo, e interpretamos que os aviões estão sendo voados agora, ou seja, "Flying" qualifica o estado dos aviões neste exato momento. Sob outro ângulo, ou sob outra estrutura (e daí nasce a ambiguidade), temos "Flying" como substantivo. Neste caso, quem se torna perigoso é o próprio "voar" do avião, e não mais os "aviões voadores" da primeira estrutura. Cushing (1997) expõe seu ponto de vista quanto à ambiguidade das seguintes maneiras, esclarecendo que:
In general, ambiguity is the presence of two or more meanings in a word, phrase, sentence, or passage. (Cushing, 1997, p. 7)

Ambiguity is an ever-present source of potencial air-ground misunderstanding. (Cushing, 1997, p. 7)

A seguir, ilustramos ambiguidade com um novo exemplo. Desta vez, retirado do livro de Fromkin, Rodman \& Hyams (2007).

Ex.: "The boy saw the man with the telescope."

Devido a diferentes estruturas, podemos interpretar tal sentença por dois ângulos distintos, não possibilitando identificar aquele que o autor teve a intenção de expor. Tanto se pode dizer que o homem foi visto pelo garoto através de um aparelho de telescópio, como se pode afirmar que o telescópio pertencia ao homem, quem fora visto com o aparelho, pelo garoto.

Segundo Cushing (1997), temos cinco componentes para o sistema de entendimento natural de uma língua. São eles: léxicos, sintaxe, semântica, pragmática da linguagem em pauta e um entendimento geral não baseado na língua. Léxico de uma língua é a descrição formal de seu vocabulário. As demais definições serão tratadas separadamente a seguir, conforme exposto por Cushing (1997) e outros autores.

\subsection{Ramos da Línguística}

\subsubsection{Fonética/Fonologia}

Conforme Fiorin (2003), a fonética trabalha com os sons propriamente ditos, como eles são produzidos, percebidos e que aspectos físicos estão envolvidos em sua produção. A fonologia, por sua vez, opera com a função e organização desses sons em sistemas. As diferenças combinatórias dos sons de sílabas (constituídas por consoantes e vogais de acordo com os morfemas de cada língua) são estudadas pela fonologia.

Cushing (1997), em seu trabalho aplicado à aviação, entende a fonética de forma semelhante a Fiorin: como sendo os sons da linguagem, o estudo de como a fala soa. Diferentemente da fonologia, que estuda os padrões de sons de uma linguagem, como se formam padrões de sons numa fala.

\subsubsection{Sintaxe}

Esta área da linguística, segundo Fiorin (2003), tem por propósito estudar a estrutura das sentenças. Ela estuda como itens lexicais (palavras) estão dispostos na frase e das frases num discurso, bem como a relação lógica das frases entre si. Os princípios envolvidos na 
estruturação das sentenças de uma língua são parte de nossa competência linguística.

De acordo com Cushing (1997), sintaxe de uma língua é a especificação formal de seus padrões gramaticais, as regras ou princípios que determinam relações escalares da gramática de enlaces arbitrários entre as palavras.

Sobre outro foco, temos a análise de sintaxe feita por Cushing (1997), que define como sendo a parte da gramática que representa o conhecimento das sentenças por parte do falante, suas estruturas e como elas fazem sentido dentro do contexto proposto.

\subsubsection{Semântica}

Semântica vem a constituir, por sua vez, nosso terceiro ramo linguístico. Semântica é o estudo do significado. Incide sobre a relação entre significantes, tais como palavras, frases, sinais e símbolos, e o que eles representam, a sua denotação. A semântica linguística estuda o significado usado por seres humanos para se expressar através da linguagem.

Segundo Fiorin (2003), não é pertinente estudar o mundo material, mas estudar como as línguas o interpreta e categoriza, atribuindo-lhe sentido. Eis um ponto de partida para uma semântica linguística, preocupada com a unidade e diversidade dos sentidos nas línguas naturais, e não mais subordinada às categorias ditadas por alguma instância hierarquicamente superior (o Real, o Pensamento, o Cérebro, etc).

Já conforme Cushing (1997), semântica de uma língua é como os significados são convencionados pelas sentenças da linguagem. Conforme o autor, semântica é o estudo dos significados linguísticos de morfemas, palavras, frases e sentenças. Já o estudo de como o contexto afeta o significado - por exemplo, como a sentença "It's cold in here" pode ser interpretada como "close the windows" em algumas situações - é chamado de pragmática.

\subsubsection{Pragmática}

A pragmática, como nosso último ramo de análise linguística, estuda os significados a partir de um contexto extralinguístico: discursivo, situacional, etc. Ela estuda as condições que governam a utilização da linguagem, a prática linguística. Conforme Fiorin (2003), um dos domínios de fatos linguísticos que exigem a introdução de uma dimensão pragmática nos estudos linguísticos é a enunciação, ou seja, o ato de produzir enunciados, que são as realizações linguísticas concretas.

Conforme Cushing (1997), pragmática é como uma linguagem é usada e entendida dentro de um dado contexto.
Grice (1957) estabelece uma distinção entre dois tipos de significado, o "significado do falante" - de caráter pragmático - e o "significado convencional" de natureza semântica. Na proposta de Grice (1957), o primeiro está relativamente desvinculado do segundo, ou seja, o que o falante intenciona comunicar não está necessariamente relacionado ao significado convencional (Grice, 1957). O significado do falante, não estando totalmente subordinado ao código, pode ser inferido por processos diferenciados da decodificação gramatical e lexical. Neste sentido, é central o conceito de 'implicatura': uma inferência sobre a intenção do falante, que resulta da decodificação de significados e da aplicação de princípios conversacionais. Ou seja, as implicaturas do tipo conversacional são inferências não convencionais e não marcadas discursivamente por conectivos como "portanto", sendo fruto da capacidade racional dos falantes (Grice, 1957).

Já segundo Levinson (2007), a distinção entre sentença e enunciação é de importância fundamental tanto para a semântica como para a pragmática. Essencialmente, queremos dizer que sentença é uma entidade teórica abstrata, definida numa teoria da gramática, enquanto uma enunciação é a emissão de uma sentença, um análogo de sentença ou fragmento de sentença, num contexto efetivo.

\subsection{Miscommunication ${ }^{3}$}

De acordo com Astin (1962), miscommunication pode ser analisado como um caso particular de fraco alinhamento (acoplamento) de agentes de estado mental, especificamente num caso onde há divergências nos resultados esperados pela comunicação. Astin (1962) põe comunicação como uma ação, e miscommunication sob as perspectivas de falha na comunicação (quando o emissor falha ao tentar produzir um efeito esperado), falha de percepção (quando o receptor não consegue estabelecer uma conexão cognitiva com o que o emissor tentou descrever), ou ambas.

Cushing (1997) aborda o conceito de "wishful hearing" (ouvimos o que queremos ouvir), que faz parte do processo de miscommunication. Em um caso típico de "wishful hearing", retirado do livro Fatal Words (1997),

\footnotetext{
3 Para que não haja uma tradução livre, por sua vez errônea, e com a finalidade de garantir suas características originais da língua inglesa este trabalho irá utilizar a palavra miscommunication tal como é escrita pelo inglês moderno.

${ }^{4}$ Utilizaremos o termo wishful hearing, assim como o termo miscommunication, em seu escrito padrão na língua inglesa, pelos mesmos motivos expostos ao último. Entenderemos wishful hearing como termo designativo de casos onde somos levados a entender aquilo que esperamos ouvir, ou seja, assumimos condições errôneas como certas, deixando-nos levar pela expectativa criada acerca de uma determinada comunicação bilateral específica, conforme em Cushing (1997).
} 
temos um voo de instrução, onde a altitude mantida era entre 12 e 14 mil pés. Tanto instrutor como aluno pensaram ter ouvido uma autorização para curvar à esquerda na proa 010 , descendo para 10 mil pés. Contudo, durante a descida e passando 10.700 pés, o controlador disse que o havia autorizado descer para 12 mil, e não 10 mil pés! $O$ instrutor explica:

99 por cento de todas as autorizações daquela área eram dadas para 10 mil pés, e eu, como instrutor, estava condicionado a sempre descer para 10 mil pés em vários outros voos. O controlador deve ter dito 12 mil, mas eu estava programado para 10 mil. (Cushing, 1997, p. 47)

\section{Metodologia}

O artigo se baseou em uma revisão bibliográfica, na qual livros, materiais e fontes oficiais foram utilizados com a finalidade de coletar o máximo de informações úteis. Foram feitas pesquisas diretamente em relatórios oficiais de acidentes, em que, possivelmente, uma questão linguística pode ter sido um dos fatores contribuintes. A metodologia utilizada para categorizar as informações foi na forma de tabela, a partir da qual pudemos analisar e apreciar os resultados, apresentados na discussão.

Inicialmente, colocamos em pauta a questão da língua, e sua maneira como interfere no desenrolar de uma ação rotineira de cabine. Deste modo, procuramos colocar em pauta a seguinte questão: Como a língua, e suas derivações linguísticas, podem influenciar uma determinada situação e possivelmente levá-la ao miscommunication? Ainda, o quão importante é a questão da comunicação para o desenvolver de um voo seguro?

Desta maneira, iniciamos nossos estudos baseados em uma fonte principal de pesquisa, o livro Fatal Words (Cushing, 1997). Nele, pudemos encontrar cerca de dez exemplos que deram sustentação à nossa hipótese inicial, que era de que relevantes problemas de comunicação, decorrentes do equivocado uso do inglês, seja como L1 ou L2, podem resultar em acidentes aéreos.

Após a fase de coleta de dados, balizamos nossos estudos na criação de um quadro para expressar os resultados. Este quadro foi organizado para ilustrar as comunicações cruciais de cada exemplo. Nele, há comunicações literais do que foi dito pelo piloto ou pelo controlador, especificamente em cada caso, bem como o que foi entendido pelo ouvinte e o que foi realmente quisto dizer. A seguir, Figura 2, temos uma breve ideia de como este quadro fora organizado.
Figura 2. Quadro de esclarecimento do problema comunicativo (ilustr.)

\begin{tabular}{|l|l|l|}
\hline O que foi dito & $\begin{array}{l}\text { O que o controlador } \\
\text { entendeu }\end{array}$ & $\begin{array}{l}\text { O que o piloto } \\
\text { quis dizer }\end{array}$ \\
\hline & & \\
\hline & & \\
\hline & & \\
\hline & & \\
\hline & & \\
\hline & & \\
\hline & & \\
\hline
\end{tabular}

Fonte: Elaborado pelo autor (2012).

Progredimos nosso trabalho no sentido de criar uma interligação entre nossos exemplos e os diversos ramos linguísticos, já mencionados anteriormente. A organização destes problemas se deu na forma de um quadro, que nos permitiu a classificá-los em um ou mais ramos linguísticos, havendo, contudo, sempre um determinado nível a se destacar perante os outros. $\mathrm{Na}$ Figura 3, temos um exemplo de como o quadro fora confeccionado, respeitando os reais resultados obtidos nesta pesquisa.

Figura 3. Quadro de classificação do problema de comunicação do acidente em ramos linguísticos (ilustr.)

\begin{tabular}{|l|l|l|l|l|}
\hline Exemplo & $\begin{array}{c}\text { Fonética/ } \\
\text { Fonologia }\end{array}$ & Semântica & Sintaxe & Pragmática \\
\hline 1$)$ & & & & \\
\hline 2$)$ & & & & \\
\hline 3$)$ & & & & \\
\hline 4$)$ & & & & \\
\hline 5$)$ & & & & \\
\hline 6$)$ & & & & \\
\hline 7$)$ & & & & \\
\hline 8$)$ & & & & \\
\hline
\end{tabular}

Fonte: Elaborado pelo autor (2012).

O quadro foi construído para ligarmos os quatro ramos linguísticos que estamos analisando, aos exemplos extraídos dos livros citados.

Logo após a finalização do quadro, nos detemos a apreciá-lo sobre uma perspectiva de como estaríamos contribuindo para a segurança de voo, e nesta premissa baseamos toda nossa discussão sobre os resultados obtidos. Durante a discussão dos resultados, procuramos explicar o motivo pelo qual classificamos estes acidentes, de acordo com seu respectivo nível linguístico.

Paralelamente, margeamos nossa dissertação sobre os resultados no sentido da criação de um gráfico. Neste 
trabalho mostramos não somente a possível existência de uma interface entre a segurança de voo e a linguística, como também a quantificamos, de maneira estatística, na forma de um gráfico. Neste instrumento, analisamos a quantidade de ocorrências linguísticas nos acidentes, em outras palavras, respondemos qual seria o nível linguístico que poderia causar mais miscommunication durante uma comunicação entre pilotos, ou entre pilotos e ATC.

\section{Resultados}

A fim de ilustrar e identificar sistematicamente os exemplos e os erros de comunicação decorrentes de cada exemplo sugerimos a apresentação do quadro da Figura 4. Nele, estão pontuados o que foi dito pelo piloto/controlador, o que foi entendido pelo piloto/ controlador e o que realmente o piloto/controlador quis dizer.

Ainda, como resultado de nossas pesquisas, e baseado na obra Fatal Words de Cushing (1997), postulamos a identificação das sentenças, possíveis causadoras de acidentes aeronáuticos, sob uma ótica linguística, mais especificamente, sob diferentes ramos da linguística. A partir disso, a Figura $\mathbf{5}$ apresenta os mesmos dez (10) exemplos expostos no quadro anterior, onde vemos questões de miscommunication presentes ${ }^{5}$.

Figura 4. Quadro de esclarecimento do problema comunicativo para os exemplos apresentados

\begin{tabular}{|l|l|l|}
\hline O que foi dito & O que foi entendido pelo piloto/controlador & O que o piloto/controlador quis dizer \\
\hline 1) "we are now at takeoff" & (15a) waiting at the takeoff point & (15b) "already on the takeoff roll" \\
\hline 2) "can we hold, ask him if we can - hold" & Can we continue? Ask him if we can - continue. & "Can we abort? Ask him if we should abort." \\
\hline 3) "we are running out of fuel" & Avianca 52 isn't at an emergency & "we are in an emergency" \\
\hline 4) "blast of power" & last of power & "Full power" \\
\hline 5) "pass to the left of the tower" & Pass to the pilot's left of the tower & "Pass to the tower's left of the tower" \\
\hline 6) "cleared seven" & Cleared ils procedure, ils 27 & "Cleared 7 thousand feet." \\
\hline 7) "climb to five zero (FL 050)" & Climb two five zero (FL 250) & "Climb to five zero (FL 050)" \\
\hline 8) "(may we cross?) Hold short" & oh sure & "hold short" \\
\hline $\begin{array}{l}\text { 9) "the other Aircraft on the approach in front } \\
\text { of you has landed; you are number one for } \\
\text { the approach" }\end{array}$ & cleared for the approach. & "Wait for further authorization" \\
\hline 10) "resume your own navigation" & $\begin{array}{l}\text { you are on your own so far as direction and } \\
\text { altitude are concerned. }\end{array}$ & $\begin{array}{l}\text { "Resume you own navigation, however, keep it } \\
\text { on the standard instruments procedures." }\end{array}$ \\
\hline
\end{tabular}

Fonte: Elaborado pelo autor(2012).

Figura 5. Quadro de classificação dos casos estudados em termos dos ramos linguísticos

\begin{tabular}{|c|c|c|c|c|}
\hline Exemplo & Fonética/Fonologia & Sintaxe & Semântica & Pragmática \\
\hline 1) "we are now at takeoff" & & & & $\mathrm{x}$ \\
\hline 2) "can we hold, ask him if we can - hold" & & & $\mathrm{x}$ & $x$ \\
\hline 3) "we are running out of fuel" & & & & $x$ \\
\hline 4) "blast of power" & $x$ & & & \\
\hline 5) "pass to the left of the tower" & & & & $x$ \\
\hline 6) "cleared seven" & & & & $x$ \\
\hline 7) "climb to five zero (FL 050)" & $x$ & $\mathrm{x}$ & & \\
\hline 8) "(may we cross?) Hold short" & $x$ & & & $x$ \\
\hline $\begin{array}{l}\text { 9) "the other Aircraft on the approach in front } \\
\text { of you has landed; you are number one for } \\
\text { the approach" }\end{array}$ & & & & $x$ \\
\hline 10) "resume your own navigation" & & & & $x$ \\
\hline
\end{tabular}

Fonte: Elaborado pelo autor (2012)

\footnotetext{
${ }^{5}$ Posteriormente, conduziremos uma discussão acerca dos resultados onde seremos capazes de pontuar casos inerentes aos resultados, antes não percebidos pela literatura estudada.
} 
Como conclusão dos nossos resultados, trazemos o quadro acima como campo de considerações. Nele, pudemos verificar a interface entre os diferentes ramos da linguística e os exemplos de acidentes. Ainda, conforme os exemplos dois (2), sete (7) e oito (8), percebemos casos onde uma mesma ocorrência poderá ficar atrelada a dois ramos linguísticos. Para a discussão dos resultados, reservamos uma explicação um pouco mais detalhada sobre cada acidente do quadro ilustrado pela Figura 5, bem como a argumentação sobre porque os classificamos sob tais ramos.

\section{Discussão}

Nesta sessão analisaremos pontualmente cada exemplo exposto pela Figura 4, assim como a organização de mais conceitos aprendidos com os resultados. Inicialmente, vejamos os casos separadamente:

1) Neste primeiro exemplo, comunicação ocorrida no caso de Tenerife, temos o ramo linguístico da Pragmática. Neste clássico acidente da aviação mundial, envolvemos controladores falantes de inglês como L2, e mais duas aeronaves. Uma, holandesa, provida de tripulação também falante de inglês como L2, enquanto outra, americana, sob a bandeira da Pan Am, ocupada por tripulantes nativos de inglês. Neste caso, percebemos claramente a miscommunication entre o controlador espanhol e o piloto holandês, quando foi dito a frase "We are now at takeoff'. Para o piloto holandês, e segundo Cushing (1997) traz, ele pensava que havia ficado claro para o controlador espanhol que eles estavam já na corrida de decolagem. Entretanto, não foi isso que aconteceu, e, justamente pelo controlador ter interpretado de maneira secundária, temos o acidente classificado sob uma ótica da pragmática. Ao utilizar aquela frase, e dentro do contexto daquele dia, o piloto da KLM quis deixar claro que já estava na rolagem de decolagem. Contudo, o que pode ter feito sentido para o piloto, aparentemente não fez para o controlador da torre de Tenerife, impedindo que o mesmo solicitasse que o KLM abortasse, e provocando o acidente. Quanto ao controlador, vemos que ele entendeu, segundo Cushing (1997, p. 9), "Waiting at the takeoff point". Como podemos ver, são considerações bem opostas entre o "significado do falante" e o "significado da sentença" dita pelo experiente piloto da KLM. Levantamos a questão do inglês como L2 utilizado por ambos os lados. Estamos cientes das limitações do nosso trabalho, mas um estudo avaliando questões da pragmática e do que realmente fez sentido para cada lado, e por que, deve ser considerado como pesquisa posterior.
2) Em "Can we hold, ask him if we can - hold", classificamos o caso sob os ramos linguísticos da Semântica e da Pragmática. Esta frase fora retirada do acidente do voo Air California 336. Encontramos questões semânticas muito fortes quanto a palavra "hold". Como já exposto, a semântica é o estudo do significado. Ela incide sobre a relação entre significantes, tais como palavras, frases, sinais e símbolos, e o que eles representam, a sua denotação. A palavra "hold" pode ter mais de um significado, e assim, gerando a miscommunication devido ao entendimento errôneo do sentido do verbo. Ainda, percebemos traços da pragmática quando o comandante do voo faz uso da linguagem, aplicado a este contexto, de maneira inadequada, fazendo o copiloto pensar o oposto do "significado do falante".

3) Em "We are running out of fuel", o classificamos sob o ramo linguístico da Pragmática. Este caso, vemos ocorrido no voo Avianca 52. Mais uma vez, e se confirmando a repetência quanto ao ramo linguístico da pragmática dentre os casos aeronáuticos citados por Cushing (1997), chegamos ao nosso terceiro real acidente documentado e trazido neste trabalho de pesquisa. Quando fora dito "We are running out of fuel", o piloto colombiano quis claramente dizer "we are on emergency", sendo esta última sentença o "significado do falante", ou seja, o que o falante quis realmente dizer. Contudo, e devido ao uso incorreto da linguagem (daí a categorização como pragmático), o piloto não se fez entender, gerando um caso nítido de miscommunication. $\mathrm{O}$ que o controlador estadunidense entendeu, foi que eles não estavam em emergência devido ao combustível, e poderiam prosseguir o voo sem comprometer a segurança ou integridade física da aeronave. Ainda, assim como no nosso primeiro exemplo, temos pilotos falantes de inglês como L2, e levanto o mérito do uso inadequado da sentença (pragmática) como possivelmente correlacionado ao fato de serem fluentes em espanhol, e não em inglês. Assim, a interferência da língua materna, tão como a falta de domínio da língua inglesa, são questões bastante relevantes, mas limitamos nossas pesquisas à apenas especulações quanto ao assunto, sugerindo pesquisas futuras com esta abordagem.

4) Em "Blast of power", o classificamos sob o ramo linguístico da Fonética/Fonologia. Neste caso temos impregnado, ainda, a questão da instrução aérea. Durante uma aproximação final para um determinado aeroporto, o instrutor disse ao aluno: "Blast of Power", para assim, prevenir que o estol ocorresse. Como visto na sessão de Pressupostos Teóricos, a fonética 
estuda como os sons de uma língua estão estruturados. Desta maneira, percebemos a ocorrência de pronuncia semelhante com a sentença "Last of Power", que tem significado totalmente oposto, e fora assim interpretada pelo aluno em instrução, o fazendo achar que necessitasse menos potência. Este exemplo, apresentado por Cushing (1997), nos faz perceber o quão comum tais problemas de natureza fonética podem ser.

5) Classificamos o quinto exemplo sob o nível linguístico da Pragmática. Quando temos "Pass to the left of the tower", temos também a questão da ambiguidade, onde não há como saber de qual esquerda o controlador está se referindo. A palavra "left" tanto pode se referir à esquerda da torre como a esquerda do piloto, as quais são diagonalmente opostas. Ainda, esta ocorrência se categoriza como exemplo de pragmática pelo contexto da situação ser de significativa importância para o entendimento por parte do ouvinte. Finalmente, por acontecer a ambiguidade, o piloto certamente pode ter interpretado a sentença com um significado - Significado Convencional, de Grice (1957) diferentemente da intenção inicial do controlador Significado do Falante, também de Grice (1957).

6) O sexto exemplo também é classificado sob o ramo linguístico da Pragmática. Ao termos uma transmissão de rádio, a qual nos diz: "cleared seven", possivelmente nada entenderemos, pois, estarmos autorizados ao número sete, a nada nos remete. E aí está nossa primeira evidência de pragmática, o contexto é inseparável deste nível linguístico. Sem ele, não conseguimos interpretar. Contudo, onde ocorre a miscommunication especificamente? Ela ocorre mais uma vez na diferença entre o significado do falante (o controlador neste caso), e o significado da sentença (o que "cleared seven" diz por si só). Neste acidente, conforme exposto por Cushing (1997), o piloto destinatário desta mensagem via rádio interpretou tal sentença como autorização para iniciar o procedimento ILS da pista 27. Todavia, o piloto havia apenas o autorizado a descer para sete mil pés. Tal tipo de miscommunication pode certamente gerar um início inadvertido de procedimento para pouso e causar maiores prejuízos.

7) Em "Climb to five zero (FL 050)", classificamos a situação sob os ramos linguísticos da Fonética/Fonologia e o da Sintaxe. Neste caso, conforme Cushing (1997) nos mostra, temos uma autorização para subida inicial até o nível de voo 050. Contudo, por questões fonéticas/ fonológicas, e também homofônica, como no exemplo 4 , temos a interpretação do piloto de que ele estaria autorizado a subir, imediatamente, para o nível 250. Tal miscommunication se deu pela completa semelhança entre a preposição em inglês "to" e o numeral "two", onde colocado antes do "...five zero" e por omissão do obrigatório "zero" antes do "...five zero" (para assim categorizar o regulamentar três números designativo de nível de voo), deu a conotação de que o nível autorizado fosse o "...two five zero". Por isso, entendemos tal problema como pertencente ao grupo da fonética/ fonologia. Em discussão com outros estudiosos da linguística, percebemos a questão da sintaxe também presente neste caso. Como anteriormente citado, a sintaxe estuda o campo de regras que ordenam as construções e frases. Deste modo, avaliamos necessária a presença de uma preposição "to" antecedendo o nível de voo autorizado, e estando ela de fato presente na frase. Entretanto, o piloto não se deu conta de tal regência da sintaxe, fazendo, mesmo assim, a errônea interpretação da sentença. Ressaltamos nesse caso, a importância da fraseologia padrão, a qual adota a preposição "to" anteriormente ao nível de voo dado e que construiria esta frase da seguinte maneira: "Climb to flight level zero five zero".

8) O caso "(May we cross?) Hold Short" pode ser classificado sob os ramos linguísticos da Fonética/ Fonologia e da pragmática. De acordo com Cushing (1997), quando o piloto pergunta ao controlador "May we cross", automaticamente o piloto espera por uma resposta positiva, confirmando sua intenção. $\mathrm{O}$ piloto não faria tal pergunta se soubesse que há alguma aeronave que atrapalharia seu caminho. Deste modo, e como Cushing (1997) coloca, há a ocorrência de "wishful hearing". Somada a esta questão encontramos, na resposta dada pelo controlador, um exemplo claro de semelhança de pronúncia. Ao responder "Hold short", o piloto entendeu "Oh sure", como sendo, assim, uma sentença afirmativa para o cruzamento. Esse tipo de ocorrência pode ser muito grave caso gere uma incursão inadvertida à pista em uso por outro avião. Assim, decidimos classificá-lo como interferência pelo modo como a expressão "Hold short" pode ter soado, e também no ramo pragmático, uma vez que o contexto situacional levou os interlocutores a interpretações diferentes.

9) Neste nono ponto, classificamos o exemplo sob o ramo linguístico da Pragmática. Mais uma vez encontramos uma sentença onde claramente o uso da linguagem e seu contexto levou o ouvinte a interpretar de maneira incorreta, ocasionando, por conseguinte, a miscommunication. A pragmática se faz presente quando ocorre uma errada interpretação, por parte 
do piloto, quanto à frase proferida pelo controlador de tráfego aéreo. Ao dizer "The other aircraft on the approach in front of you has landed; you are number one for the approach", o órgão de controle estava apenas informando a situação ao piloto, e informando sua sequência de pouso, sendo este o "sentido do falante". Porém, não foi assim interpretado pelo aviador. Para o piloto, esta sentença significou que ele estava autorizado a iniciar o procedimento para pouso, gerando assim, tal miscommunication sob a ótica da pragmática. Ainda, o contexto ao qual ele estava aplicado provavelmente o ajudou a pensar que estaria sendo autorizado ao procedimento, talvez estivesse o piloto em órbita ${ }^{6}$.

10) Enfim, no último caso pesquisado, classificamos "Resume your own navigation" sob o ramo linguístico da Pragmática. Quando o controlador informa ao piloto "Resume your own navigation", em fraseologia padrão, o piloto passa a reassumir a navegação, não estando condicionado à navegação sob vetoração $\operatorname{radar}^{7}$ provida pelo órgão de controle. Contudo, também não é uma autorização para que a aeronave se desvie da navegação pré-estabelecida no plano de voo apresentado. A pragmática aparece presente quando o piloto entendeu o sentido da sentença como sendo, segundo Cushing (1997), "you are on your own so far as direction and altitude are concerned".

Uma vez estudados separadamente e visto porque classificamos cada exemplo de acidente sob uma ótica diferente da linguística, podemos verificar certa padronização quanto aos resultados. Padronização a qual se sustenta sobre alicerces repetitivos de acontecimentos. Os exemplos 1, 2, 3, 5, 6, 9 e 10 foram classificados como pertencentes ao nível linguístico da pragmática. Como já visto, pragmática é, conforme Cushing (1997), uma linguagem usada e entendida dentro de um dado contexto. Não nos esqueçamos do contexto aplicado a todos os exemplos estudados, os quais se categorizam pela complexidade de informações a serem gerenciadas por um, dois ou três tripulantes em certos casos. Algumas vezes, tratamos de contextos de instrução de voo, onde há o fator pedagógico aplicado. Enfim, estaremos sempre analisando contextos de natureza complexa, sendo analisados por seres humanos passíveis a erros, e que

\footnotetext{
${ }^{6}$ Entenderemos por órbita como procedimento padrão de espera, realizado pelas aeronaves, sobre um determinado ponto. Tal procedimento visa a melhor separação do tráfego aéreo bem como outras finalidades (RIBEIRO, Elones. 2011. Comunicação pessoal).

${ }^{7}$ Compreenderemos por vetoração radar como o procedimento provido por algum órgão de controle, onde, momentaneamente, o piloto é obrigado a obedecer uma navegação passada ao aviador, na maioria dos casos via comunicação rádio (RIBEIRO, Elones. 2011. Comunicação pessoal).
}

devem ainda conduzir uma comunicação bilateral junto a um órgão de controle específico, o qual passará altas quantidades de informações, sendo tudo justificado pelo inquestionável princípio da segurança.

A comunicação, principal agente para se estabelecer tal contato, fora executada, em grande parte dos casos, entre pilotos e ATC, na língua inglesa, onde todos os envolvidos a possuíam como L1. Ora, considerando tais fatos, como explicar a incontrolada reincidência da questão da pragmática, sendo esta intrínseca ao processo comunicativo? Para isto, devemos analisar que a pragmática se aplica ao uso da língua, e conforme exposto no capítulo de Pressupostos Teóricos, Levinson (2007) categoriza a pragmática como o estudo das relações entre a língua e o contexto, que são básicas para uma descrição da compreensão da linguagem. Deste modo, retomamos a questão sob outra abordagem, por que houve sobressalente expressão da pragmática, nos resultados, frente os outros ramos linguísticos? Antes de considerarmos tal dúvida, apreciemos o gráfico inerente aos resultados na figura a seguir.

Figura 6. Gráfico de análise quantitativa das ocorrências de ramos da linguística relacionados aos casos estudados

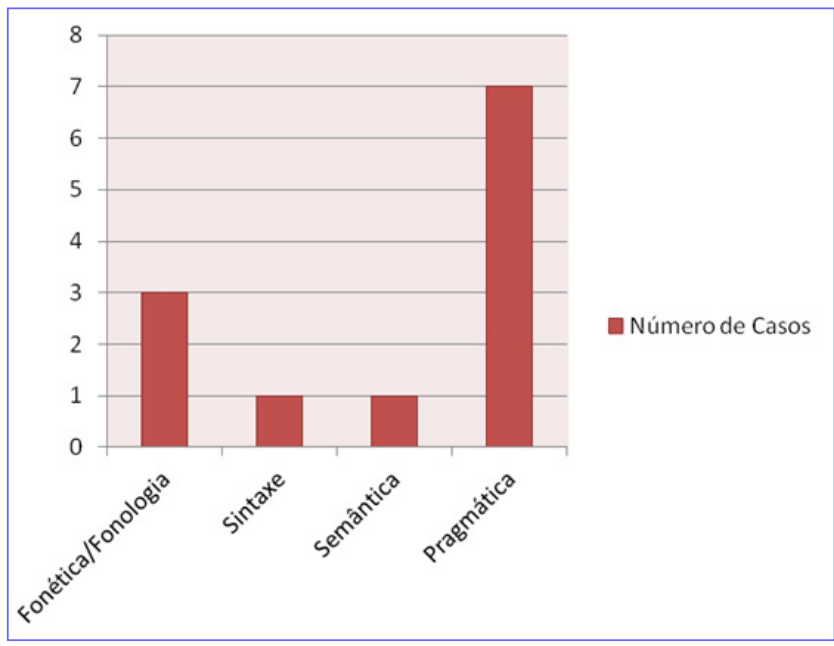

Fonte: Elaborado pelo autor (2012).

O gráfico acima nos remete a percebermos a importância do nível linguístico da pragmática frente aos acidentes estudados. Reconhecemos as limitações deste trabalho, não o categorizando como matéria de estudo conclusiva, dado a pequena quantidade de amostras de acidentes/incidentes coletados.

Uma vez que temos quase todos os agentes da comunicação envolvidos no processo, pertencentes a uma mesma classe de falantes nativos da língua inglesa, podemos concluir que estes se entendem, uns aos outros, com maior facilidade. No caso da fonética/ fonologia, concluímos que a maioria possuía padrões 
de pronúncia, Ou seja, muito provavelmente, falantes nativos de uma mesma língua pronunciam e formam os fonemas de maneira muito semelhante, não dando margem para que ocorresse miscommunication. Assim, concluímos ainda que esta fora a segunda maior causadora de miscommunication dentre os agentes da comunicação.

Do mesmo modo, avaliamos, como apresentado no gráfico acima, poucas ocorrências para os ramos linguísticos da semântica e da sintaxe. Esta última, por exemplo, é apenas vista como agente secundário de classificação para o exemplo número 7. Atribuímos a este resultado o fato da fraseologia padrão, utilizada nas comunicações técnicas aeronáuticas, ser totalmente autônoma quanto às normatizações da sintaxe que rege o inglês comum. Posto de outra forma, vemos a fraseologia aeronáutica como uma linguagem simplificada do inglês comum. Visando a segurança e a eficácia, e que muitas vezes se sobrepõe a ordem lógica de construção de uma sentença, a fraseologia normatizada prioriza apenas os pontos mais importantes do conteúdo que se quer passar, diversas vezes contraindo expressões ou omitindo partículas complementares ${ }^{8}$ da oração.

Também com apenas uma ocorrência dentre os exemplos dados, temos o nível da semântica. Este nível, conforme explicado no capítulo 2, sessão 2.1, subsessão 2.2.3, é responsável pelo estudo do significado das palavras e foi particularmente achado em um caso inesperado. Quando iniciadas as pesquisas, atribuímos grande parte da miscommunication como mal entendimento por diversos fatores, entre eles a ambiguidade. Esta, por sua vez, se sustentou conforme exposto por Cushing (1997) que apresenta uma estrutura ambígua como decorrente de possíveis análises sintáticas distintas, categorizando significados diferentes a certas palavras, e daí a ambiguidade estaria diretamente ligada à semântica. Como os resultados ironicamente nos demonstram, a semântica fora apenas determinante em um caso. Mesmo assim, este caso também pode ser categorizado como pertencente ao nível da pragmática. Fomos levados a concluir que, apesar da semântica estudar os significados das palavras, e estes significados poderem estar ligados a miscommunication, este nível teve pouca influência quanto ao desfecho dos acidentes pesquisados.

Assim, destacamos o nível linguístico mais presente dentre os acidentes relatados nos resultado, a pragmática. Cushing (1997) traz, igualmente, o

\footnotetext{
${ }^{8}$ Entenderemos por partículas complementares como sendo palavras presentes numa sentença que tem por função ligar as palavras principais (verbos, substantivos e adjetivos), bem como dar coesão e fluidez ao texto. São partículas complementares a uma oração os adjuntos adnominais, preposições e conjunções.
}

uso da pragmática e sua inteligibilidade como sendo dependente do contexto. Do mesmo modo, devemos retomar ao conceito de Grice (1957), onde ele estabelece uma distinção entre dois tipos de significado, o "significado do falante" - de caráter pragmático - e o "significado convencional" - de natureza semântica. Estabelecida tal distinção, temos o significado do falante ligado direta a pragmática e, assim, muito importante para a apreciação dos resultados.

Uma vez expostos tais conceitos, retomemos a questão anteriormente levantada: por que houve sobressalente expressão da pragmática, nos resultados, frente os outros ramos linguísticos? Para atingirmos uma resposta conclusiva, devemos verificar que houve sete de dez exemplos que foram organizados dentro do ramo da pragmática. Em todos estes foram possível analisar a diferenciação entre o "significado do falante" e o "significado da sentença", tal como é exposto por Grice (1957).

Antes de concluirmos as discussões dos resultados, constatemos a importância deste trabalho quanto à segurança de voo, principalmente na tangente de comunicações aeronáuticas. Visto a importância da pragmática na ocorrência de miscommunication, propomos, paralelamente, pesquisas futuras sobre o assunto. Ainda, propomos mais atenção à consciência situacional ${ }^{9}$ dos tripulantes, sempre quando estabelecendo comunicações bilaterais. Julgamos importante se manter dentro da fraseologia padrão conforme exposta pela $\mathrm{OACI}^{10}$, para que haja a mitigação dos problemas comunicativos, bem como redução de problemas ligados a pragmática, importante nível aqui estudado.

Da mesma maneira, a fraseologia padrão procura aproximar o significado do falante com o significado da sentença, sendo isto de fundamental importância para a prevenção de miscommunication ligado a questões da pragmática, bem como impedir a baixa consciência situacional ${ }^{11}$ de um tripulante interferir quanto a sua interpretação à frase exposta a si.

Os retornos de conhecimento proporcionados pelos acidentes são de incomensurável ajuda para o desenvolvimento seguro da atividade aérea do futuro.

\footnotetext{
9 Entenderemos consciência situacional conforme exposto no livro Safety at the Sharp End, de Rhona Flin, Paulo O'Connor, Margaret Crichton (2011, p. 33): "Situational awareness is the perception of the elements in the environment within a volume of time and space, the comprehension of their meaning and the projection of their status in the near future".

${ }^{10}$ Organização de Aviação Civil Internacional

${ }^{11}$ Temos total convicção de que é de extrema dificuldade mensurar a consciência situacional de um indivíduo, esteja ele inserido a uma atividade ou não. Utilizamos este termo no sentido de qualificar um tripulante ou controlador de voo que esteja sob um ambiente de alta complexidade, alta carga de trabalho, e sua consciência da situação esteja voltada a outra atividade, que não seja a de se comunicar.
} 
A organização destes acidentes, tal como trazida por este trabalho monográfico, nos permite melhor compreendermos o mundo da aviação ao qual estamos inseridos, e do qual participamos ativamente. O nível linguístico que mais se destacou nesta pesquisa fora, sem dúvida, a pragmática. Contudo, os outros, e especialmente a fonética/fonologia, merecem atenção e dedicação, pois muitas vezes também podem estar atrelados a miscommunication observada em acidentes aeronáuticos.

\section{Conclusão}

A organização destes acidentes, tal como trazida por este trabalho, nos permite melhor enxergar o mundo da aviação ao qual estamos inseridos, e do qual participamos ativamente. Como vimos, o nível linguístico que mais se destacou nesta pesquisa fora, sem dúvida, a pragmática. Contudo, os outros, e especialmente a fonética/fonologia, por abordarem questões inerentes à pronúncia, merecem atenção e dedicação, pois muitas vezes também podem estar atrelados a miscommunication observada em acidentes aeronáuticos.

Uma vez ultimada as pesquisas bibliográficas, nos deparamos certamente com a sensação de querer mais. Deste modo, e como já visto ao longo da discussão, propomos como pesquisas futuras a análise de mais casos referentes à miscommunication, associando-os a ramos linguísticos para melhor compreendê-los. Ainda, nos casos de Tenerife e do voo Avianca 52, levantamos a questão da L1 dos locutores como possível interferência. Assim, pesquisas no sentido de identificar as possíveis interferências da L1 dos sujeitos nas comunicações técnicas aeronáuticas em inglês como L2, devem ser levadas em consideração. Por conseguinte, certas deficiências conclusivas que este trabalho possa apresentar poderão ser suplantadas por trabalhos posteriores.

\section{Referências}

Austin JA. How to Do Things with Words. London, UK: Harvard University Press; 1962.

Cushing S. Fatal Words: communication clashes and aircraft crashes. Chicago: The University of Chicago Press; 1997. PMCid:PMC1284027.

Ellis R. The study of second language acquisition. Oxford: Oxford University Press; 1994.

Fiorin JL. Introdução à linguística. 2aㅡ ed. São Paulo: Contexto; 2003. PMid:14999340.

Fiorin JL. Introdução à linguística. $5^{\mathrm{a}}$ ed. São Paulo: Contexto, 2008.

Flin R, O'connor P, Crichton M. Safety at the sharp end: na guide to non-technical skills. Burlington: Ashgate; 2011. PMCid:PMC3178242.

Fromkin V, Rodman R, Hyams N. An introduction to language. 8a ed. Boston: Thompson, 2007. PMCid:PMC2660096.

Griffin T. An optimistic perspective on tourism's sustainability in sustainable Tourism. Edited by Rob Harris, Tonny Griffin, and Peter Williams. Oxford: Butterworth-Heinemann, 2002. p. 24-32. PMid:11876581.

Grice HP. Meaning. Philosophical Review. 1957; 66:377-388. In: Grice (1989). Also in: Rosenberg JF, Travis C (Editors). Readings in the Philosophy of Language. Englewood Cliffs: Prentice-Hall; 1971.

Gunnemark EV. Countries, People and Their Languages (a Geolinguistic Handbook). Gothenburg, Sweden; 1991.

Hill AA. Introduction to linguistic structures: from sound to sentence in English. Harcourt, Brace; 1902.

Kanki BG, Palmer MT. Communication and crew resource management in Cockpit Resource Management. Edited by Earl L. Wiener, Barbara G. Kanki, and Robert L. Helmreich. San Diego, CA: Academic Press; 1993. p. 99-135.

Levinson SC. Pragmatics. Cambridge, UK: Cambridge University Press; 2007.

Spinassé KP. Os conceitos Língua Materna, Segunda Língua e Língua Estrangeira e os falantes de línguas alóctones minoritárias no Sul do Brasil. Revista Contingentia. 2006; 1.

Unesco. Position Paper. Education in a Multilingual World. Published in 2003 by the United Nations Educational, Scientific and Cultural Organization. Paris, France. 